\title{
Modeling and demonstration of a saturated Ni-like Mo X-ray laser
}

\author{
J. Nilsen, Y. Li, J. Dunn, T.W. Barbee, Jr., and \\ A.L. Osterheld
}

This article was submitted to

$7^{\text {th }}$ International Conference on X-ray Lasers, Saint-Malo, France, June $19-23,2000$

\section{August 21, 2000}

U.S. Department of Energy

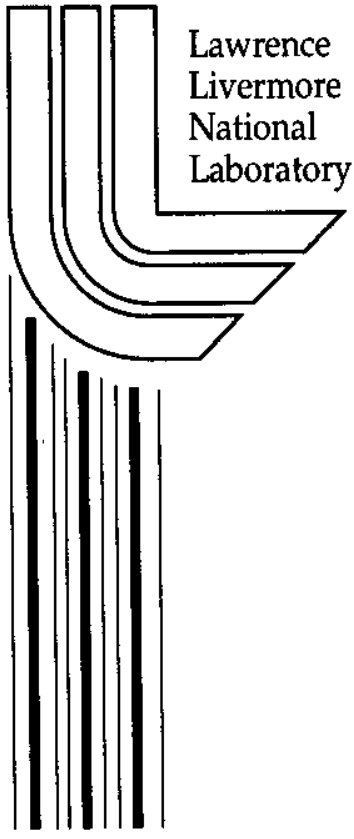

Approved for public release; further dissemination unlimited 


\section{DISCLAIMER}

This document was prepared as an account of work sponsored by an agency of the United States Government. Neither the United States Government nor the University of California nor any of their employees, makes any warranty, express or implied, or assumes any legal liability or responsibility for the accuracy, completeness, or usefulness of any information, apparatus, product, or process disclosed, or represents that its use would not infringe privately owned rights. Reference herein to any specific commercial product, process, or service by trade name, trademark, manufacturer, or otherwise, does not necessarily constitute or imply its endorsement, recommendation, or favoring by the United States Government or the University of California. The views and opinions of authors expressed herein do not necessarily state or reflect those of the United States Government or the University of California, and shall not be used for advertising or product endorsement purposes.

This is a preprint of a paper intended for publication in a journal or proceedings. Since changes may be made before publication, this preprint is made available with the understanding that it will not be cited or reproduced without the permission of the author.

This report has been reproduced directly from the best available copy.

Available to DOE and DOE contractors from the Office of Scientific and Technical Information

P.O. Box 62, Oak Ridge, TN 37831

Prices available from (423) 576-8401 http://apollo.osti.gov/bridge/

Available to the public from the National Technical Information Service

U.S. Department of Commerce 5285 Port Royal Rd., Springfield, VA 22161 http://www.ntis.gov/

OR

Lawrence Livermore National Laboratory Technical Information Department's Digital Library http://www.llnl.gov/tid/Library.html 


\title{
Modeling and demonstration of a saturated Ni-like Mo X-ray laser
}

\author{
Joseph Nilsen, Yuelin Li*, James Dunn, Troy W. Barbee, Jr., and Albert L. Osterheld \\ Lawrence Livermore National Laboratory, Livermore, CA 94550
}

\begin{abstract}
The technique of using a nsec pulse to preform and ionize the plasma followed by a psec pulse to heat the plasma has enabled us to achieve saturated laser output for low- $\mathrm{Z}$ neon-like and nickel-like ions driven by small lasers with less than ten joules of energy. In this work we present and model recent experiments done using the COMET laser at Lawrence Livermore National Laboratory to illuminate slab targets of Mo up to $1 \mathrm{~cm}$ long with a one joule, $600 \mathrm{ps}$ prepulse followed $700 \mathrm{psec}$ later by a five joule, one psec drive pulse. The experiments demonstrate saturated output on the Ni-like Mo $3 \mathrm{~d}^{9} 4 \mathrm{~d}^{1} \mathrm{~S}_{0} \rightarrow 3 \mathrm{~d}^{9} 4 \mathrm{p}^{1} \mathrm{P}_{1}$ laser line at $18.9 \mathrm{~nm}$. The small signal gain and gain length product are estimated by measuring the laser output versus target length. Experiments are done using multilayer mirrors to obtain two-dimensional images of the output aperture of the laser and to measure the total laser energy as a function of various parameters such as the delay between the short and long pulses and the energy of the two pulses. To model the experiments the LASNEX code is used to calculate the hydrodynamic evolution of the plasma and provide the temperatures and densities to the XRASER code, which then does the kinetics calculations to determine the gain. The temporal and spatial evolution of the plasma is studied both with and without radiation transport included for the $4 \mathrm{f}$ and $4 \mathrm{p} \rightarrow 3 \mathrm{~d} \mathrm{Ni-like} \mathrm{Mo} \mathrm{resonance} \mathrm{lines.} \mathrm{High} \mathrm{gains} \mathrm{are} \mathrm{predicted} \mathrm{for} \mathrm{both} \mathrm{the}$ $3 d^{9} 4 d^{1} S_{0} \rightarrow 3 d^{9} 4 p^{1} P_{1}$ laser line at $18.9 \mathrm{~nm}$ and the $3 d^{9} 4 f^{1} P_{1} \rightarrow 3 d^{9} 4 d^{1} P_{1}$ photopumped line which is observed to lase at $22.6 \mathrm{~nm}$.
\end{abstract}

\section{Introduction}

Most researchers today use some variant of the prepulse technique [1-2] to achieve lasing in Ne-like or $\mathrm{Ni}$-like ions. As a result the Ne-like $3 \mathrm{p}{ }^{1} \mathrm{~S}_{0} \rightarrow 3 \mathrm{~s}{ }^{1} \mathrm{P}_{1}$ laser line now dominates the laser output as was predicted two decades ago. This technique illuminate solid targets with several pulses. The first pulse is used to create a large-scale length plasma, which is in the correct density range for gain and has sufficiently small density gradients for laser propagation. The subsequent pulses are then absorbed more efficiently and heat the plasma to lasing conditions. Typical pulse durations range from 100 ps to $1 \mathrm{~ns}$ and typically use 100 to $1000 \mathrm{~J}$ of energy. In the above techniques the pulse duration is held constant but the contrast and separation between pulses is varied. A recent variant of these techniques is the use of a nsec prepulse followed by a psec drive pulse. This approach was first used to demonstrate lasing at 32.6 $\mathrm{nm}$ in Ne-like $\mathrm{Ti}$ at the Max Born Institute (MBI) [3] using less than 10 joules of energy. The Ti experiments were reproduced at Lawrence Livermore National Laboratory (LLNL) using the COMET laser and extended to Ni-like Pd at $14.6 \mathrm{~nm}$ [4] and very recently to Ni-like Mo at $18.9 \mathrm{~nm}$ [5]. In this paper we present experiments that demonstrate saturated output on the Ni-like Mo $3 d^{9} 4 d^{1} S_{0} \rightarrow 3 d^{9} 4 p$ ${ }^{i} \mathrm{P}_{1}$ laser line at $18.9 \mathrm{~nm}$. The small signal gain and gain length product are estimated by measuring the 
laser output versus target length. Experiments are done using multilayer mirrors to obtain twodimensional images of the output aperture of the laser and to measure the total laser energy as a function of various parameters such as the delay between the short and long pulses and the energy of the two pulses. We also model the Ni-like Mo experiments done with the COMET laser to understand the plasma conditions present and what gain is possible on different transitions. For Ni-like Mo we calculate lasing on both the $4 d^{1} S_{0} \rightarrow 4 p{ }^{1} P_{1}$ line at $18.9 \mathrm{~nm}$ and the $4 \mathrm{f}^{1} \mathrm{P}_{1} \rightarrow 4 \mathrm{~d}^{1} \mathrm{P}_{1}$ line at $22.6 \mathrm{~nm}$. For the $4 \mathrm{f}^{1} \mathrm{P}_{1}$ $\rightarrow 4 \mathrm{~d}^{1} \mathrm{P}_{1}$ line we discuss the role of the photopumping mechanism and present the measured gain for this line.

\section{Plasma Modeling}

To estimate what gain might be achieved on various transitions in Ni-like Mo we did LASNEX one dimensional (1D) computer simulations to model a Mo slab illuminated by a $1 \mathrm{~J}, 600 \mathrm{psec}$ gaussian pulse followed $700 \mathrm{psec}$ later by a $5 \mathrm{~J}, 1$ psec gaussian pulse from a $1.05 \mu \mathrm{m} \mathrm{Nd}$ laser. The laser is focused to a $120 \mu \mathrm{m}$ wide by $1.2 \mathrm{~cm}$ long line. The $700 \mathrm{psec}$ delay between the long and short pulse is peak to peak. This is similar to the conditions used to demonstrate lasing in Ni-like Mo at the COMET laser facility. The LASNEX calculations include an expansion angle of 15 degrees in the dimension perpendicular to the primary expansion so as to simulate 2D effects.

Using the LASNEX calculated densities and temperatures as input to the XRASER code, the gains of the laser lines were calculated including radiation trapping effects for the four strong $4 \mathrm{f}$ and $4 \mathrm{p} \rightarrow 3 \mathrm{~d}$ resonance lines in Ni-like Mo. Bulk Doppler effects due to the expansion of the plasmas were also included. The XRASER atomic model includes all 107 detailed levels for levels up to $n=4$ in Ni-like Mo.

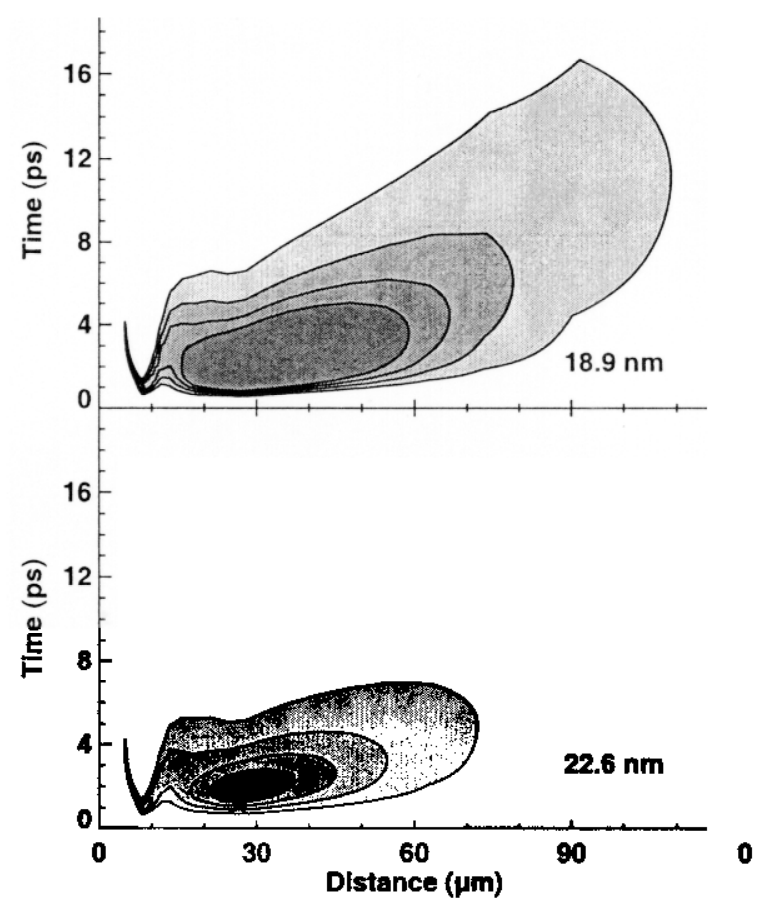

Fig. 1. Spatial and temporal evolution of the gain for the Ni-like Mo laser lines at 18.9 and $22.6 \mathrm{~nm}$. Contours represent gain values greater than $120,90,60$, and $30 \mathrm{~cm}^{-1}$, respectively. Line transfer is included in this calculation. The short pulse laser drive peaks at $1 \mathrm{ps}$ on this time scale. 
Calculations predict two dominant laser lines that can be divided into two classes. First there is the $4 \mathrm{~d}$ ${ }^{1} \mathrm{~S}_{0} \rightarrow 4 \mathrm{p}{ }^{1} \mathrm{P}_{1}$ line at $18.9 \mathrm{~nm}$ that is populated by monopole collisional excitation of the Ni-like ground state. The other strong line is the $4 \mathrm{f}^{1} \mathrm{P}_{1} \rightarrow 4{ }^{1} \mathrm{P}_{1}$ line at $22.6 \mathrm{~nm}$ that is populated primarily by photopumping on the strong $3 \mathrm{~d}^{1} \mathrm{~S}_{0} \rightarrow 4 \mathrm{f}^{1} \mathrm{P}_{1}$ transition.

Figure 1 shows contours of the gain versus space and time for the 18.9 and $22.6 \mathrm{~nm}$ laser lines for the nominal drive conditions described above. The short pulse laser peaks at 1 psec on this time scale so the evolution during the long pulse is not shown. The horizontal axis gives the distance from the target surface in the direction of the plasma expansion. The gain contours, from darkest to lightest, represent gains greater than $120,90,60$, and $30 \mathrm{~cm}^{-1}$. The highest gain for the $18.9 \mathrm{~nm}$ line exceeds $300 \mathrm{~cm}^{-1}$ at a distance of $28 \mu \mathrm{m}$ from the surface and at a time of $2 \mathrm{ps,} \mathrm{which} \mathrm{is} \mathrm{just} \mathrm{after} \mathrm{the} \mathrm{time} \mathrm{of} \mathrm{peak}$ illumination. However this gain region is near the critical density surface and has steep gradients, which would make it difficult to propagate any significant distance. Looking at the electron density gradients it appears that the region that is more than $45 \mu \mathrm{m}$ from the surface should allow good propagation. If we look at $50 \mu \mathrm{m}$ from the surface the gain peaks at $3 \mathrm{ps}$ with a value of $170 \mathrm{~cm}^{-1}$. Gain $>30 \mathrm{~cm}^{-1}$ persists until $10 \mathrm{ps}$. The simulations show that the $22.6 \mathrm{~nm}$ line also has very strong gain but is more confined in space and time. Therefore we expect the spatially averaged gain for this line will be lower.

To give an idea of the plasma conditions we can look $50 \mu \mathrm{m}$ from the surface at a time of $6 \mathrm{ps}$. The electron density is $6.4 \times 10^{19} \mathrm{~cm}^{-3}$ with an electron temperature of $295 \mathrm{eV}$ and an ion temperature of 47 $\mathrm{eV}$. The gain on the 18.9 and $22.6 \mathrm{~nm}$ laser lines are 90 and $38 \mathrm{~cm}^{-1}$ respectively. The gradient in the electron density is $-1.7 \times 10^{22} \mathrm{~cm}^{-4}$. This gradient would only refract the $18.9 \mathrm{~nm}$ laser line by $14 \mu \mathrm{m}$ away from the target surface as it propagated over a $1 \mathrm{~cm}$ distance.

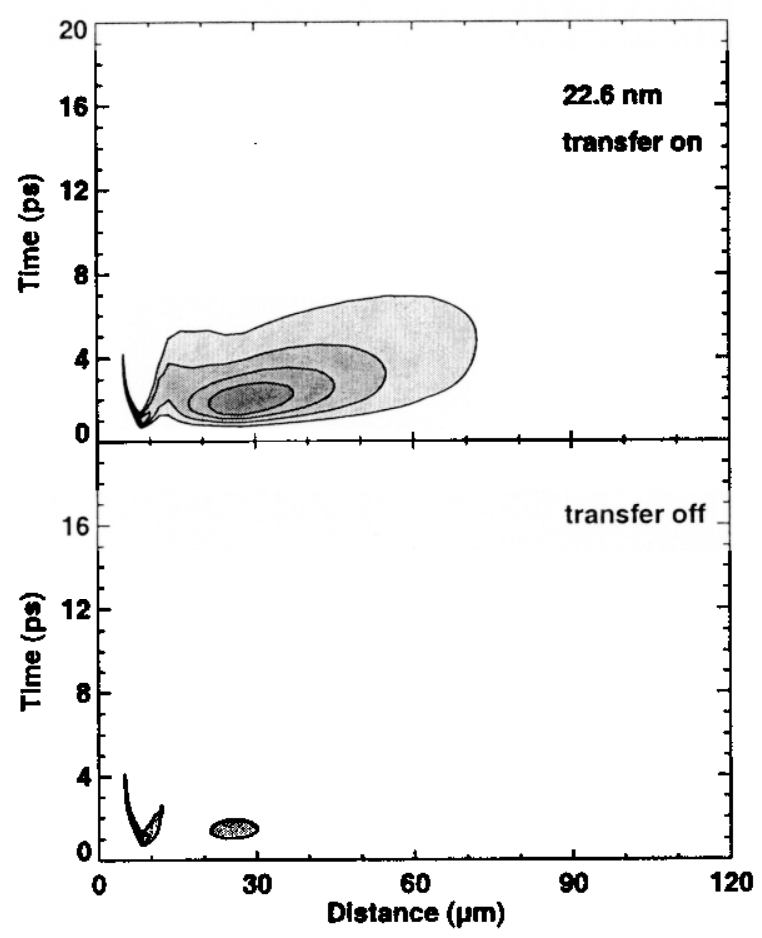

Fig. 2. Spatial and temporal evolution of the gain for the Ni-like Mo $4 f \rightarrow 4 d$ laser line at $22.6 \mathrm{~nm}$ for the cases with the line transfer turned on and off. With the line transfer off the gain disappears. This shows the dramatic effect that photopumping has on driving the gain in this laser line. The short pulse laser drive peaks at $1 \mathrm{ps}$ on this time scale. Contours represent gain values greater than $120,90,60$, and $30 \mathrm{~cm}^{-1}$, respectively. 
One would normally not expect gain on the $4 \mathrm{f} \rightarrow 4 \mathrm{~d}$ laser line at $22.6 \mathrm{~nm}$ because its upper laser state is the $4 \mathrm{f}^{1} \mathrm{P}_{1}$ level which is depopulated by the rapid radiative decay to the ground state via the strongest resonance line. However, in this plasma, the $3 \mathrm{~d}^{\prime} \mathrm{S}_{0} \rightarrow 4 \mathrm{f}^{\prime} \mathrm{P}_{1}$ line is optically thick and radiation trapping allows a very large radiation field to build up on this line and therefore populate the $4 \mathrm{f}^{1} \mathrm{P}_{1}$ upper laser state by the self-photopumping process. To understand the role of the self-photopumping process on the gain of the Ni-like Mo laser lines, we did the XRASER calculations with the line transfer package turned off so that all the $n=4 \rightarrow n=3$ resonance lines are optically thin and the self-photopumping process is absent. For the $18.9 \mathrm{~nm}$ laser line there is a modest reduction in the gain. For the $22.6 \mathrm{~nm}$ laser line, Fig. 2 shows contours of the gain with line transfer on and off. The gain contours, from darkest to lightest, represent gains greater than $120,90,60$, and $30 \mathrm{~cm}^{-1}$. The gain of the $22.6 \mathrm{~nm}$ laser line disappears without the photopumping process except for a very small region near the critical density surface. This clearly shows that photopumping is the mechanism that drives this line. A detailed analysis of the photopumping for the analogous $3 \mathrm{~d} \rightarrow 3 \mathrm{p}$ line in Ni-like Ti can be found in Ref. [6].

One issue that needs to be addressed is the difference between the laser system driven with $100 \mathrm{ps}$ pulses versus those driven with 1 ps pulses. Since we have only begun to model the Ni-like Mo and we have done much more extensive modeling for Ne-like $\mathrm{Ti}$ we would like to briefly discuss the transient nature of the Ne-like Ti laser. From our modeling of the $\mathrm{Ti}$ laser driven by a 1 ps pulse we would characterized the lasing on the neon-like titanium lines at 32.6 and $30.1 \mathrm{~nm}$ as quasi steady state. The heating time is shorter than the ionization time but longer than the equilibration time for the upper laser states. The big difference between driving a titanium plasma with a 1 psec pulse versus a 100 psec pulse is the comparison with the ionization time. For the 1 psec pulse one expects the plasma to lase after the psec drive while with a $100 \mathrm{psec}$ pulse one would expect the lasing on the rising edge of the pulse before the neon-like stage has been completely ionized. The modeling of the Ne-like Ti is described in great detail in Ref. [6]. We expect similar behavior in Ni-like Mo.

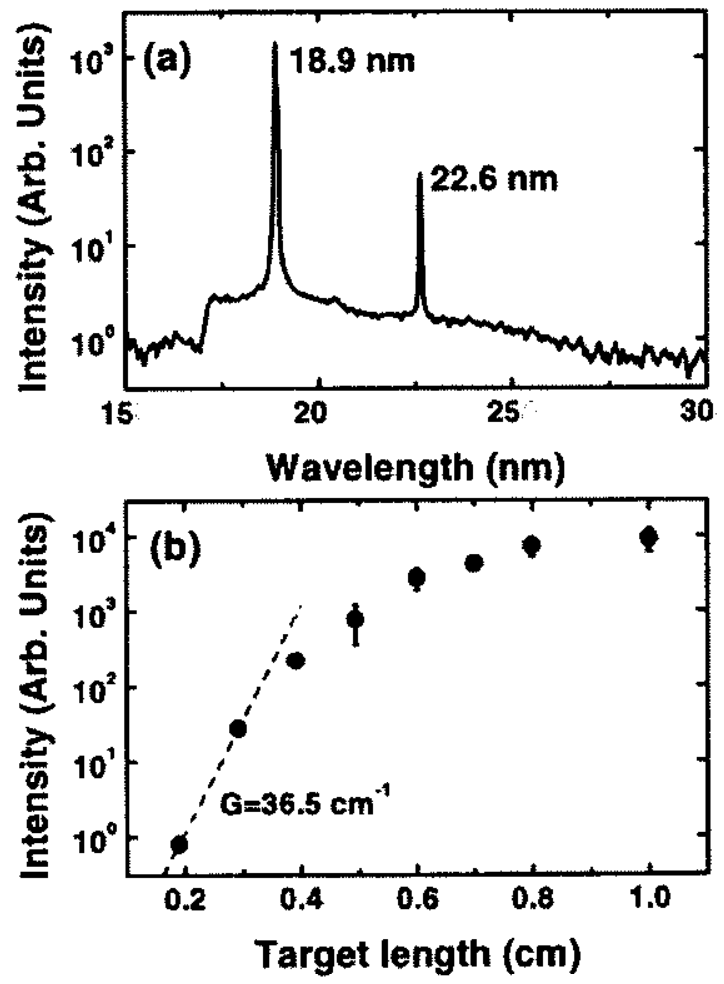

Fig. 3. (a) Intensity versus wavelength for a 1-cm long Mo target shows lasing on the $18.9 \mathrm{~nm}$ and $22.6 \mathrm{~nm}$ Ni-like Mo lines; (b) Intensity versus target length for the Ni-like Mo $18.9 \mathrm{~nm}$ laser bine. The small signal gain is measured to be $36.5 \mathrm{~cm}^{-1}$ with an overall gain-length product of $\mathbf{1 6 . 6}$ as the laser line saturates. The bong pulse and short pulse energies were $1.1 \mathrm{~J}$ and $5.0 \mathrm{~J}$, respectively, with a $700 \mathrm{ps}$ delay. 


\section{Experiments}

Saturated operation of the Ni-like Mo X-ray laser was demonstrated on the compact multipulse terawatt (COMET) laser system at LLNL. A 600 ps long pulse and a 1 ps short pulse beam from a table-top, $1.053 \mu \mathrm{m}$ Ti:Sapphire-Nd:Glass hybrid chirped pulse amplification laser system are sent into the target chamber. The short pulse is focused on to the target to form an $80 \mu \mathrm{m}$ by $1.1-\mathrm{cm}$ line focus. The long pulse is defocused to be two times broader in order to ensure a better overlap with the short pulse and to produce a more uniform lateral plasma. The laser can be fired every 4 minutes so many experiments can be done each day. To more efficiently use the short-lived population inversion, we implemented a traveling wave excitation setup using a 5-segment stepped mirror. We did experiments to compare the $X$-ray laser output with and without the traveling wave. In the case without the traveling wave, the step mirror was replaced by a flat one.

We used both near field imaging and on-axis spectroscopy to investigate the $\mathrm{X}$-ray laser performance. Normally, the $x$-ray laser output is sent to an on-axis flat field grating spectrometer that is coupled to a back-thinned, CCD and has wavelength coverage of $14-35 \mathrm{~nm}$. The spectrometer gives time-integrated spectra with angular resolution in the plane of the normal of the target and the axis of the line focus. To do near-field imaging we use three $\mathrm{Mo}_{2} \mathrm{C} / \mathrm{Si}$ multilayer mirrors. The first mirror is spherical and images the output aperture of the X-ray laser onto a back-thinned X-ray CCD. The other 2 flat mirrors, one with normal and the other with $45^{\circ}$ incidence, fold the beam to obtain a magnification of 14.1. With the 24$\mu \mathrm{m}$ pixels of the $\mathrm{CCD}$, this gives a spatial resolution of $1.7 \mu \mathrm{m}$. The calculated total reflectivity of the multilayer imaging system is $5.9 \%$ with a bandwidth of $1 \mathrm{~nm}$ at $18.9 \mathrm{~nm}$. To protect the multilayer mirrors from target debris, attenuate the X-ray laser intensity, and block the visible light, aluminum filters of various thickness were used. A more detailed description of the Ni-like Mo experiments can be found in Refs. [7-8].

Using the traveling wave geometry dramatically enhances the X-ray laser output by one to two orders of magnitude and makes the X-ray laser output less sensitive to the delay between the long and short pulse. For that reason we used the traveling wave geometry for all subsequent experiments. We did a series of experiments using the near-field imaging system to determine that a delay of 700 ps works well for the conditions we are using.

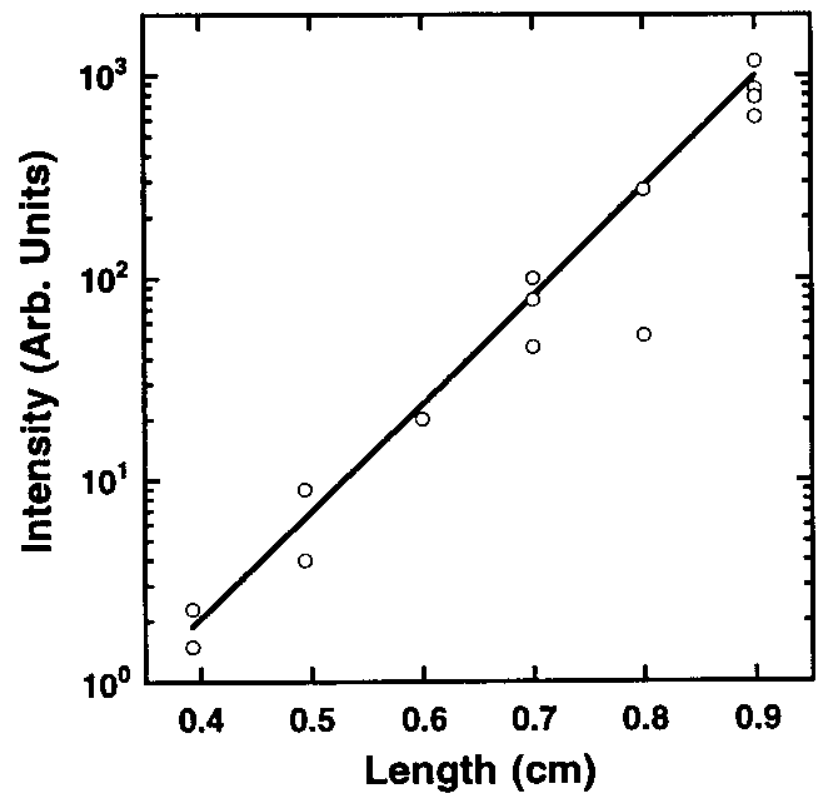

Fig. 4. Intensity versus length for the Ni-like Mo $22.6 \mathrm{~nm}$ laser line. The small signal gain is estimated to be $13 \mathrm{~cm}^{-1}$ with no indication of saturation. The long pulse and short pulse energies were $1.1 \mathrm{~J}$ and $5.0 \mathrm{~J}$, respectively, with a 700 ps delay. 
With this delay, Fig. 3(a) presents the spectrum for a full length target $(1 \mathrm{~cm})$ that shows the two strong laser lines at $18.9 \mathrm{~nm}$ and $22.6 \mathrm{~nm}$. We then varied the target length while holding the line focus constant to measure the small signal gain and estimate an overall gain-length product of 16.6 for the $18.9 \mathrm{~nm}$ line. From the measured intensity versus length shown in Fig. 3(b) we estimate the small signal gain of $36.5 \mathrm{~cm}^{-1}$ on the $18.9 \mathrm{~nm}$ line and believe this line has reached saturation intensity as the gain curve flattens out. For the $22.6 \mathrm{~nm}$ laser line Fig. 4 shows the intensity versus length from which we estimate a gain of $13 \mathrm{~cm}^{-1}$. For this line we do not see any sign of saturation. Both the 18.9 and $22.6 \mathrm{~nm}$ laser lines are very robust to changes in laser conditions and allow good gain-length measurements to be made.

Using the near field imaging diagnostics we did many experiments to study the laser output as a function of the delay and contrast between the long and short pulse. We could also observe how the beam quality changed as a function of how many times we shot on the same target. From those experiments we could measure the absolute energy of the $18.9 \mathrm{~nm}$ laser line and verify independently that we had reached saturation. Fig. 5 shows a near field image of the $18.9 \mathrm{~nm} \mathrm{X}$-ray laser line which used $4 \mathrm{~J}$ in the long pulse and $5 \mathrm{~J}$ in the short pulse with a 700 ps delay. The optical laser is incident from the right with the vertical direction parallel to the target surface. The plasma expands in the horizontal direction. The absolute position of the target surface is uncertain but we estimate its position as $0 \mu \mathrm{m}$ on the horizontal axis based on plasma emission. The FWHM of the lasing region is $90 \mu \mathrm{m}$ in the vertical direction and $70 \mu \mathrm{m}$ in the horizontal direction with peak emission about $30 \mu \mathrm{m}$ from the target surface. The measured output energy is $2.3 \mu \mathrm{J}$ with an estimated intensity of $5 \mathrm{GW} / \mathrm{cm}^{2}$. This exceeds the calculated saturation intensity of $2-3 \mathrm{GW} / \mathrm{cm}^{2}$ estimated by our calculations. For the nominal case of $1 \mathrm{~J}$ in the long pulse the X-ray laser intensity is about one-half the value observed for the $4 \mathrm{~J}$ long pulse but still reaches saturation intensity.

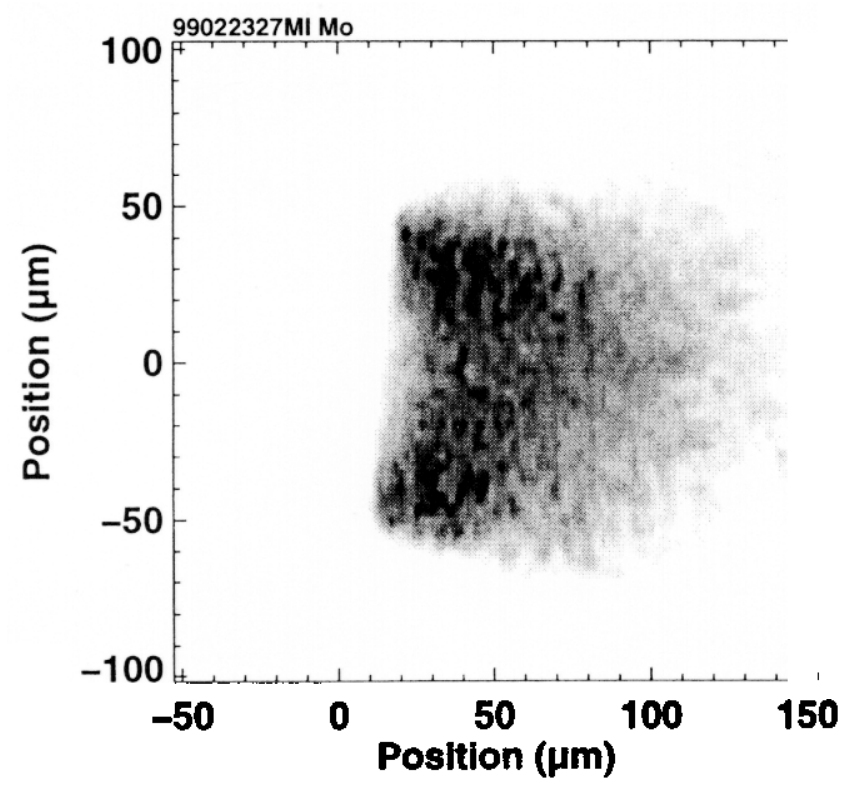

Fig. 5. Near-field image of the Ni-like Mo $18.9 \mathrm{~nm}$ laser line for a 1-cm target. The target surface is at $0 \mu \mathrm{m}$ on the horizontal axis and the pump laser is incident from the right. The long and short pulse energies are 4 and $5 \mathrm{~J}$, respectively, with a 700 ps delay between pulses. The total energy of the X-ray laser is estimated to be $2.3 \mu \mathrm{J}$. 


\section{Conclusions}

In this work we present and model recent experiments done using the COMET laser at Lawrence Livermore National Laboratory to illuminate slab targets of Mo up to $1 \mathrm{~cm}$ long with a $1 \mathrm{~J}, 600 \mathrm{ps}$ prepulse followed $700 \mathrm{psec}$ later by a $5 \mathrm{~J}, 1 \mathrm{psec}$ drive pulse. The experiments demonstrate saturated output on the Ni-like Mo $3 d^{9} 4 d^{1} S_{0} \rightarrow 3 d^{9} 4 p{ }^{1} P_{1}$ laser line at $18.9 \mathrm{~nm}$. The small signal gain and gain length product are estimated to be $36.5 \mathrm{~cm}^{-1}$ and 16.6 respectively, by measuring the laser output versus target length. Experiments were done using multilayer mirrors to obtain two-dimensional images of the output aperture of the laser and to measure the total laser energy as a function of various parameters such as the delay between the short and long pulses and the energy of the two pulses. We estimate an output energy of $2.3 \mu \mathrm{J}$ for the saturated laser.

To model the experiments the LASNEX code is used to calculate the hydrodynamic evolution of the plasma and provide the temperatures and densities to the XRASER code, which then does the kinetics calculations to determine the gain. The temporal and spatial evolution of the plasma is studied both with and without radiation transport included for the $4 \mathrm{f}$ and $4 \mathrm{p} \rightarrow 3 \mathrm{~d}$ Ni-like Mo resonance lines. High gains are predicted for both the $3 d^{9} 4 d^{1} S_{0} \rightarrow 3 d^{9} 4 p{ }^{1} P_{1}$ laser line at $18.9 \mathrm{~nm}$ and the $3 d^{9} 4 f^{1} P_{1} \rightarrow 3 d^{9} 4 d^{1} P_{1}$ photopumped line at $22.6 \mathrm{~nm}$. Gain of $13 \mathrm{~cm}^{-1}$ is measured for the photopumped line at $22.6 \mathrm{~nm}$.

Acknowledgements - The authors would like to thank Richard Ward and Andi Hazi for their support. Yuelin Li acknowledges support from Hector Baldis of the Institute for Laser Science and Applications (ILSA). This work was performed under the auspices of the U.S. Department of Energy by the University of California Lawrence Livermore National Laboratory under contract No. W-7405-Eng-48.

* Yuelin Li is currently at Argonne National Laboratory, Argonne, IL 60439

\section{References}

[1] J. Nilsen, B. J. MacGowan, L. B. Da Silva, and J. C. Moreno, Phys. Rev. A 48, 4682 (1993).

[2] J. Nilsen and J. C. Moreno, Phys. Rev. Lett. 74, 3376 (1995).

[3] P. V. Nickles, V. N. Shlyaptsev, M. Kalachnikov, M. Schnuerer, I. Will, and W. Sandner, Phys. Rev. Lett. 78, 2748 (1997).

[4] J. Dunn, A. L. Osterheld, R. Shepherd, W. E. White, V. N. Shlyaptsev, and R. E. Stewart, Phys. Rev. Lett. 80, 2825 (1998).

[5] J. Dunn, J. Nilsen, A. L. Osterheld, Y. L. Li, and V. N. Shlyaptsev, Opt. Lett. 24, 101 (1999).

[6] J. Nilsen, Y. L. Li, and J. Dunn, J. Opt. Soc. Am. B 17, 1084 (2000).

[7] Y. L. Li, J. Dunn, J. Nilsen, T. W. Barbee, Jr., A. L. Osterheld, and V. N. Shlyaptsev, J. Opt. Soc. Am. B 17, $1098(2000)$.

[8] Y. L. Li, J. Dunn, J. Nilsen, T. W. Barbee Jr., L. B. Da Silva, A. L. Osterheld, and V. N. Shlyaptsev, "Near field imaging of a saturated table top X-ray laser," SPIE Proceedings 3776 - Soft X-ray Lasers and Applications $I I I$, edited by J. J. Rocca and L. B. Da Silva (SPIE Press, Bellingham, 1999), pp. 45- 51 